\title{
A PRESERVAÇÃO DO PATRIMÔNIO ARQUITETÔNICO E SUAS RELAÇÕES COM O PLANEJAMENTO E DESENVOLVIMENTO URBANO
}

\author{
PRESERVATION OF ARCHITECTURAL HERITAGE AND ITS RELATIONSHIP WITH URBAN \\ PLANNING AND DEVELOPMENT
}

\author{
Tarcisio Dorn de Oliveira (iD) \\ Universidade Regional do Noroeste do Estado do Rio Grande do Sul, Ijuí, RS, Brasil, tarcisio_dorn@ \\ hotmail.com
}

Andréa Quadrado Mussi

Universidade Regional do Noroeste do Estado do Rio Grande do Sul, Ijuí, RS, Brasil

Franciele Zientarski Engerroff (iD

Universidade Regional do Noroeste do Estado do Rio Grande do Sul, Ijuí, RS, Brasil

DOI: http://dx.doi.org/10.31512/missioneira.v31i1.204

Recebido em: 15/02/2020

Aceito em: 25/07/2020

\begin{abstract}
Resumo: O patrimônio arquitetônico são bens que servem de referência para os habitantes de determinado local e exercem grande importância na vida cotidiana da sociedade. Muitas vezes, por mais que possam estar escondidos ou que passem despercebidos pela maioria das pessoas, estão associados a memória coletiva o individual podendo serem protegidos por leis e/ou pela própria conscientização da população sobre sua importância e significação. O presente trabalho intenta abordar, mediante pesquisa bibliográfica, a importância da salvaguarda das edificações patrimoniais para as cidades e como esta preservação relaciona-se com as questões do planejamento urbano e do desenvolvimento social local e regional. A memória urbana constitui-se pela paisagem da cidade, através da presença de edificações de todas as idades e estilos - quanto mais velho um prédio, mais história carrega em sua fachada e mais sua arquitetura dialoga com o tempo que já passou, ou seja, mais historias ele tem e pode contar. O patrimônio arquitetônico merece salvaguarda pois faz parte da memória coletiva urbana da cidade, haja visto, que o espaço urbano é um ambiente socialmente produzido e faz associações diretas sobre a trajetória das transformações do lugar - de onde e para onde a cidade expandiuse e o porquê das ações realizadas no cenário da cidade.
\end{abstract}

Palavras-chave: Arquitetura. Patrimônio. Preservação. Desenvolvimento urbano.

\begin{abstract}
Architectural heritage are assets that serve as a reference for the inhabitants of a given location and have great importance in the daily life of society. Often, as much as they may be hidden or that may go unnoticed by most people, collective memory is associated with the individual and can be protected by laws and / or by the population's own awareness of its importance and significance. The present work intends to approach, through bibliographic research, the importance of safeguarding heritage buildings for cities and how this preservation is related to the issues of urban planning and local and regional social development. Urban memory is constituted by the city's landscape, through the presence of buildings of all ages and styles - the older a building, the more history it carries on its facade and the more its architecture dialogues with the time
\end{abstract}


that has passed, that is, more stories he has and can tell. The architectural heritage deserves safeguarding because it is part of the city's urban collective memory, having seen, that the urban space is a socially produced environment and makes direct associations on the trajectory of the transformations of the place - from where and where the city expanded and the reason for the actions carried out on the city scene.

Keywords: Architecture. Patrimony. Preservation. Urban development.

\section{Considerações iniciais}

A palavra patrimônio remete refletir questões advindas e relacionadas sobre herança, e esta, pode ser coletiva ou individual, herdado dos nossos familiares e/ou deixado para as próximas gerações. A arquitetura que integra a paisagem é um modelo de patrimônio interessante, vivo e coletivo (mesmo que em âmbito individual). O patrimônio arquitetônico contribui, de forma significativa, no diálogo com o contexto urbano e no planejamento e desenvolvimento do mesmo, pois interage diretamente com a paisagem e seu entorno, conferindo informações e possibilidades de imaginação de quem o observa. Nessa perspectiva, Vilanova (2013), afirma que preservar é defender, proteger e resguardar - é exercer o direito à cidadania, à memória e à identidade.

É pertinente considerar que o patrimônio arquitetônico contitui-se no coletivo, por grupos diversos e de grande interesse para a sociedade, haja visto, que a salvaguarda da arquitetura é importante quando associada à coletividade e à preservação da memória urbana. A memória é uma aliada para a construção da identidade do corpo social e colabora para o entendimento da trajetória humana, ajudando a compreender as ações de planejamento e desenvolvimento urbano das cidades. Dessa forma, preservar é essencial para o entendimento do que nossos antepassados pensavam e como viam o mundo, pois a arquitetura, vista como arte e patrimônio, é o reflexo dos nossos pensamentos, sentimentos e demais subjetividades. Para Oliveira e Callai (2018, 143):

[...] políticas de preservação do patrimônio transformam-se em peças fundamentais e estratégicas, muitas vezes, identificadas como verdadeiros instrumentos de ordenamento da cidade. Proteger o patrimônio é manter vivas as marcas da história, assegurando a possibilidade de que as gerações futuras tomem conhecimento das manifestações produzidas socialmente ao longo do tempo, seja no campo das artes, nos modos de viver, nas crenças, lugares ou na paisagem da própria cidade, com seus atributos naturais, tangíveis e intangíveis.

O Estado é responsável por evitar o descaso com as edificações patrimoniais e o governo, como um todo, tem também a função de criar leis e fazer com que elas sejam seguidas - é dever do mesmo elaborar normas para que a preservação seja mais respeitada, além de, divulgar a importância da mesma, uma vez que, só se tem vontade de proteger aquilo que se conhece e, dessa forma, os cidadãos passam a entender o motivo quando conhecem 
e quando conscientizados do papel que bem edificado bem tem na construção da identidade urbana. Para Vilanova (2013), preservar é manter a integridade dos valores pelo/do próprio povo. Oliveira e Lopes (2018, p. 14) observam que:

O patrimônio edificado pode ser pensado enquanto suporte do imaginário e da memória social de uma localidade, ou seja, os edifícios e áreas urbanas possuidoras de valor patrimonial podem ser tomados como um ponto de apoio da construção da memória, de valor e poder como um estímulo externo que ajuda a reativar e reavivar os traços arquitetônicos na formação sócio territorial. Nesse viés, a memória coletiva moldada pelo transpor do tempo não é mais de que um passeio através da história, revisitada e materializada no presente pela arquitetura, reforçando a ligação de identidade e pertencimento do ser humano em certo tempo e espaço.

O patrimônio arquitetônico traz, desperta e proporciona um sentimento de identidade e de pertencimento para quem o olha. Quando alguém se (re) conhece mais profundamente com tais manifestações culturais, algo é acendido dentro de si, haja visto, que o patrimônio é símbolo que expressa grande valor para a coletividade podendo ser visto, sentido e vivido. Assim, a compreensão de que a preservação possui um papel fundamental para as futuras gerações faz referência para entender um pouco da história dos antepassados (tida como base). O patrimônio arquitetônico preserva a história da cidade em que está situado, pois tudo que é mantido intacto possui a finalidade de contribuir em algo do presente e para o futuro. Para Oliveira e Callai (2018, 143):

O espaço urbano contemporâneo, destituído de várias edificações e conjuntos arquitetônicos, transformam-se em espaços heterogêneos que muitas vezes não valoriza os edifícios com relevância arquitetônica remanescentes. As demolições relacionam-se principalmente com a perda da memória da evolução urbana e com o empobrecimento da ambiência que poderia ser mais diversa e rica. Estes fatores corroboram para seu futuro desaparecimento e indicam a necessidade imediata da preservação do que há, de ações de educação patrimonial e da conscientização da população quanto ao significado e importância dos prédios existentes como fator de identidade e pertencimento do cidadão com o seu local de origem.

A conservação do patrimônio contribui com questões relacionadas à sustentabilidade ambiental, uma vez que, acaba utilizando recursos financeiros e técnicos com valores inferiores no lugar de construir algo novo, a exemplo, da restauração que contribui para que o imóvel antigo com marcas do tempo seja preservado. Para manter o patrimônio arquitetônico vivo existem instrumentos e instituições legais (a nível federal, estadual e local) que defendem a proteção e a não demolição de edificações que possuem valor para a sociedade de forma coletiva. Amaral e Messias (2016) entendem que o valor patrimonial de um bem só pode ser compreendido se não houver uma ruptura da sua memória espacial e temporal (a restauração não pode modificar seu estilo inicial e nem as suas peculiaridades).

$\mathrm{O}$ artigo metodologicamente estrutura-se, através dos procedimentos, por uma pesquisa bibliográfica e documental, que trata da coleta e interpretação de dados em fontes já existentes 
e intenta refletir sobre a preservação do patrimônio arquitetônico, partindo da ideia de que esta ação colabora para o planejamento e desenvolvimento urbano.

\section{O patrimônio arquitetônico no contexto da preservação}

O ser humano, com o passar dos anos, cada vez mais precisa sentir-se parte de onde vive e precisa possuir um sentimento de pertencimento para ter interesse pela história, crenças e culturas do lugar em que vive. Entender o patrimônio arquitetônico faz parte de um conjunto coletivo que colabora para o desenvolvimento da sociedade, pois a identidade precisa ser questionada, sentida e entendida para que haja preservação da herança deixada pelos antepassados e a criação de novos cenários sociais para quem ainda está por nascer. Dessa forma, para Oliveira e Lopes (2018, p. 13-14):

O passado revela um sentimento de identidade e pertencimento trazendo consciência da sociedade às pessoas através do tempo e espaço. A arquitetura do passado propicia estabilidade, haja visto, que o futuro é o destino incerto e o presente o instante fugaz. Assim, a única certeza que o ser humano possui é a verdade vivida e materializada no e do passado. Então, a preservação arquitetônica faz-se em torno da relevância cultural e/ou morfológica, simbolizando o poder transmitido às pessoas do presente e do futuro, derivando da intenção de fazer do espaço urbano um espaço exuberante capaz de gerar emoções, reviver tradições e recapitular relações através do tempo entre o perto (presente) e o longe (passado).

Seguindo nessa perspectiva entende-se que assim como diversas coisas são usadas como referencias, não é diferente com as edificações, elas servem como base para o entendimento do desenvolvimento de grandes e pequenos centros urbanos, pois, de forma geral, ajudam na concepção da memória e suas individualidades auxiliam na percepção de um estilo arquitetônico, de um conhecimento sobre determinada época e do discernimento sobre como as gerações passadas viam o mundo. Ainda para Oliveira e Lopes (2018, p. 14):

A arquitetura vista como monumento não se limita somente à edificação (objeto), uma
vez que ela denota uma carga simbólica e abstrata, ou seja, a sua monumentalidade,
a qual tem por função trabalhar sobre o imaginário social. A arquitetura possui em si
uma monumentalidade, a qual transcende, refletida na ambiência urbana por uma ideia,
concepção e crença, haja visto, que os bens patrimoniais (objetos-símbolo) propiciam às
pessoas a possibilidade de viajar no imaginário. Dessa forma, a força desses monumentos
são ideias e imagens transpostas ao espaço e, num caminho inverso, espaço transposto
às ideias e às imagens como fruto e semente do imaginário. Assim, está na arquitetura
patrimonial a força do monumento e da monumentalidade, estando nos lugares e no
imaginário da humanidade.

Preservar o patrimônio arquitetônico é manter viva a memória de um lugar e/ou de um povo, pois uma sociedade que não preserva sua história dificilmente conseguirá planejar o seu futuro - o patrimônio arquitetônico preservado é um ativo urbano de fundamental importância para as futuras gerações. Para Bogea (2011) a memória é entendida como 
elemento fundamental na formação da identidade, na instituição de tradições e no registro de experiências significativas, devendo ser valorizada e preservada, pois preserva-la não significa atrelá-la ao passado e impedir o seu desenvolvimento, mas sim, conservar seus pilares constituintes a fim de não perder conhecimentos e identidades.

As futuras gerações só podem avançar quando conhecem o passado, pois só se modifica o futuro quando há entendimento do presente e, isso, dá-se a partir da leitura de como nossos ancestrais pensavam e desenvolviam o mundo. As lembranças quando materializadas colaboram para a imaginação e aguçam a curiosidade, querendo fazer com que se tenha mais conhecimento sobre tal, e assim, colaborando para querer fazer parte da história e ter um certo pertencimento sobre a memória coletiva - pertencer é ter a certeza de que o espaço constitui o indivíduo, tanto quanto humano constrói o espaço.

[...] práticas, representações, expressões, conhecimentos e técnicas - junto com os instrumentos, objetos, artefatos e lugares culturais que lhes são associados - que as comunidades, os grupos e, em alguns casos, os indivíduos reconhecem como parte integrante de seu patrimônio cultural. [...] o patrimônio [...] é transmitido de geração em geração e constantemente recriado pelas comunidades e grupos em função de seu ambiente, de sua interação com a natureza e de sua história, gerando um sentimento de identidade e continuidade, contribuindo assim para promover o respeito à diversidade cultural e à criatividade humana (IPHAN, 2017, s/p.).

O sentimento de pertencer é construído diariamente pelo ser humano - é ele que faz com que memórias sejam criadas e o cenários onde elas são concebidas originem a identidade e a criação de recordações a partir do sentir-se pertencente a algo. O desenvolvimento das cidades é fruto da vivencia de quem ali estancia-se, ou seja, é o reflexo de como o cidadão vê o mundo e a relação de como a arquitetura patrimonial é sentida - é o somatório dessas distintas visões de sentir, sempre em transformação, alterando o cenário urbano das cidades.

Delgado (2018) ressalta que a não proteção de bens culturais materiais põe em perigo a história e a cultura de uma região, sendo dever do Estado criar mecanismos para proteger, fiscalizar, educar coletivamente e permanentemente (mapeamento e inventário de referências culturais, registro e ação de salvaguarda), sob pena do seu sumidouro, se escoando e se enterrando na memória da omissão. Assim Choay (1996, p.18) afirma que:

A especificidade do monumento deve-se precisamente ao seu modo de atuação sobre a memória. Não apenas ele a trabalha e a mobiliza pela mediação da afetividade, de forma que lembre o passado fazendo-o vibrar como se fosse presente. Mas esse passado qualquer: ele é localizado e selecionado para fins vitais, na medida em que pode, de forma direta, contribuir para manter e preservar a identidade de uma comunidade. [...] para aqueles que edificam, assim como os destinatários das lembranças que veiculam, o monumento é uma defesa contra o traumatismo da existência, um dispositivo de segurança. 
Nessa perspectiva, em muitas cidades, questões como preservar e transformar entram em conflito, haja visto, que a alteração do cenário urbano é frequentemente discutida e o conceito de patrimônio entra em debate. A questão de preservação da memória, do passado coletivo e da identidade urbana entra diretamente em questionamento quando alinhavado com o planejamento e desenvolvimento urbano. No entanto, é salutar e urgente perceber que a transformação urbana deve sempre agregar - nunca propiciar com que o espaço urbano seja modificado de forma a perder ou retroceder em seu contexto histórico, social e cultural.

\section{0 patrimônio arquitetônico no contexto do planejamento urbano e desenvolvimento local}

É evidente que a cidade é fruto do desenvolvimento acelerado, tanto urbano quanto social, é transformada pelas ações humanas, por vezes, através de um planejamento adequado e, outras, sem o mesmo - mas tudo é resultado da expansão, crescimento da população e das peculiaridades do espaço que modificam-se e alterando o cenário urbano. Hardt et. al. (2017) destacam que ao mesmo tempo em que a formação das sociedades permitiu o compartilhamento de determinados benefícios entre os cidadãos, muitos centros urbanizados em diversos períodos anteriores foram expandidos sem a necessária atenção ao seu patrimônio, resultando em perdas incalculáveis.

É importante observar que o planejamento urbano é fundamental para a salvaguarda do patrimônio arquitetônico, uma vez que, quando uma cidade é bem planejada e sua expansão ocorre de forma ordenada, acaba-se incluído em sua perspectiva e realidade os prédios e edificações dos mais diferentes estilos e das mais variadas idades, desde às que, já existem a tempos ali ou as que são consideradas novas e contemporâneas. Nesse viés, Ribeiro e Simão afirmam que (2014, p. 3):

As características da cidade seja enquanto obra ou produto histórico tem relação
estabelecida entre a transformação e manutenção de seu tecido urbano refletindo
em condições específicas da sua materialidade como sua permanência; mas também
estabelecem diálogos intrínsecos com sua significação, com a memória, com as disputas
simbólicas que permeiam a produção do espaço a partir de sua representação e de
suas relações de poder. Diversas contradições entre materialidade, símbolo, memória,
objetividade, subjetividade e poder constroem o campo da preservação de patrimônio
cultural urbano.

No Brasil, em âmbito geral, a Constituição Federal impõe que todo município tem o dever de proteger e preservar seus bens culturais, pois trata-se de uma competência indeclinável e irrenunciável. Fica explicito que as cidades possuem diretrizes e planos diretores que, de forma geral, visam o desenvolvimento das mesmas utilizando argumentos para a defesa do patrimônio histórico e cultural e até mesmo se apropriam dele para que sejam desenvolvidas atividades sociais nos prédios em prol da sociedade. A Carta de Atenas elaborada no ano de 
1933, traz a ideia que a cidade é componente do todo, ela compõe parte econômica, social e política e seu desenvolvimento dá-se de forma geral, configurando o plano urbano regional. Em questões atinentes ao ato de preservação do patrimônio a referida Carta destaca que:

\begin{abstract}
Serão salvaguardadas se constituem a expressão de uma cultura anterior e se correspondem a um interesse geral [...]. Nem tudo o que é passado tem, por definição, direito à perenidade; convém escolher com sabedoria o que deve ser respeitado. Se os interesses da cidade são lesados pela persistência de determinadas presenças insignes, majestosas, de uma era já encerrada, será procurada a solução capaz de conciliar dois pontos de vista opostos: nos casos em que esteja diante de construções repetidas em numerosos exemplares, algumas serão conservadas a título de documentário, as outras demolidas; em outros casos poderá ser isolada a única parte que constitua uma lembrança ou um valor real; o resto será modificado de maneira útil (CARTA DE ATENAS, 1933, p. 25).
\end{abstract}

Entende-se que a preservação deve ser principalmente para bens que possuam interesse comum, porém, a ação do povo em relação a preservação das edificações depende muito de sua admiração pelas mesmas - quando existe uma relação de pertencimento ao lugar em que os cidadãos vivem, a ação de preservar torna-se mais natural e, essa naturalidade, dá-se também ao grau de informação que se possui quanto a necessidade dessa preservação e ao resgate da memória coletiva. A Carta Magna de 1988 estabelece que a política de desenvolvimento urbano, executada pelo poder público municipal, conforme diretrizes gerais fixadas em lei, tem por objetivo ordenar o pleno desenvolvimento das funções sociais da cidade e garantir o bem-estar de seus habitantes. Para Oliveira e Callai (2018, 143-144):

O espaço urbano contemporâneo, destituído de várias edificações e conjuntos arquitetônicos, transformam-se em espaços heterogêneos que muitas vezes não valoriza os edifícios com relevância arquitetônica remanescentes. As demolições relacionam-se principalmente com a perda da memória da evolução urbana e com o empobrecimento da ambiência que poderia ser mais diversa e rica. Estes fatores corroboram para seu futuro desaparecimento e indicam a necessidade imediata da preservação do que há, de ações de educação patrimonial e da conscientização da população quanto ao significado e importância dos prédios existentes como fator de identidade e pertencimento do cidadão com o seu local de origem.

As cidades possuem um estatuto onde objetiva a organização e o desenvolvimento das mesmas, nas mais diferentes áreas, e dentro deste estatuto existem diretrizes que incluem a preservação, proteção e recuperação do patrimônio. Os municípios com mais de vinte mil habitantes têm a obrigatoriedade ter um plano diretor como instrumento de desenvolvimento urbano básico. Assim, as cidades possuem a competência de promover a proteção do patrimônio histórico-cultural local, observado a legislação e a ação fiscalizadora federal e estadual.

Viana e Pacheco (2011) salientam que uma vez fixada a competência constitucional do Município em promover a proteção do patrimônio histórico, tanto sob o prisma legislativo quanto executivo, e conferidas as diretrizes gerais para o planejamento urbano municipal 
pelo Estatuto das Cidades, cabe ao Município fixar, em sua legislação, a política pública a ser implantada. Nesse sentido, destaca-se a Lei que institui o Plano Diretor, por se tratar do mais abrangente e participativo instrumento de planejamento urbano municipal.

O município então, é responsável pelo seu crescimento, pela sua expansão através da preservação e pela elaboração de um plano diretor eficaz que faz com que a memória palpável continue viva sem modificações compondo a vista corriqueira dos centros. As leis então exercem um papel de destaque dentro da relação do meio social e com a preservação e quando há colaboração do povo a legitimidade democrática ganha força uma vez que onde tem participação do cidadão nos debates tem mais controle das medidas pulicas adotadas.

Ainda Viana e Pacheco (2011) complementam que a constituição de fundos municipais de proteção ao patrimônio histórico e de sua gestão, por meio de conselhos, garantam a paridade entre governo e sociedade significa que a gestão é compartilhada. A sociedade então consegue identificar a prioridade de salvaguarda, conscientizar e de investir nesta ação por meio dos representantes nos conselhos. Para Oliveira, Müller, Wildner e Lopes (2019, p. 585586):

\begin{abstract}
A degradação da arquitetura patrimonial é uma questão preocupante nas mais diversas possibilidades de análise. Mesmo sendo amparada por uma ampla legislação para sua preservação, na prática se observam falhas e morosidade no seu cumprimento, acarretando a perda de bens patrimoniais em função da ineficiência de fiscalização. A valorização do patrimônio arquitetônico e sua inserção no cotidiano dos cidadãos permite que tais edificações sejam percebidas, constituindo-se como parte integrante do passado e da história local. A identidade e o pertencimento de uma comunidade se efetivam ao passo que o campo afetivo se relaciona com o espaço físico cotidiano, isto é, a sociedade que experiencia em seu cotidiano a presença do patrimônio tem sua autoestima e seu pertencimento consolidados.
\end{abstract}

As leis de proteção expressas nos planos diretores auxiliam na manutenção de um cenário arquitetonicamente rico. No entanto, na contramão, ainda é possível perceber que alguns bens ficam à mercê do esquecimento, por interesses particulares e até mesmo de herança de família e acabam sendo deixadas de lado propiciando seu processo de desaparecimento (demolição). As leis muitas vezes não são compridas devido a interesses particulares, uma vez que, o direito de propriedade está diretamente ligado com a proteção do patrimônio histórico, fazendo com que o desenvolvimento urbano tenho um certo empecilho, quando uma edificação é de interesse público existe defrontação entre o direito individual a propriedade e deste modo alguns gestores tem dificuldade para regulamentar as diretrizes impostas nos planos diretores. Nesse sentido o interesse coletivo de preservação de memória deve estar acima do que o interesse individual de propriedade. Para Cardoso, Goldenstein, Mendes e Gorgulho (2011, p. 3): 
O patrimônio pode vir a ser a mola propulsora do desenvolvimento socioeconômico local, e que a preservação pode tornar-se princípio de ativos culturais e turísticos relevantes para as cidades. É esta capacidade de gerar desenvolvimento que vai estimular e garantir a preservação deles. Ao contrário do que muitos acreditam, a existência desse patrimônio protegido não pode ser vista como um fardo inútil e um entrave ao crescimento, mas como um importante ativo a ser explorado em prol do desenvolvimento

A crescente urbanização gera grandes lacunas no processo de desenvolvimento, pois evidencia meios de exclusão que cristalizam-se nos desequilíbrios locais, regionais, urbanos e rurais. Para Hardt et. al. (2017) a intensidade de transformação do ambiente das cidades contemporâneas tem gerado inúmeras alterações do suporte natural e das próprias bases do sistema antrópico. Por decorrência desse cenário, amplia a complexidade e as dificuldades da gestão das heranças patrimoniais.

É notável o grande preconceito com a lembrança materializada, haja visto, que no Brasil é possível perceber que os monumentos e edificações valor histórico, cultural e/ou arquitetônico sofrem frequentemente ataques de degradações (físicas e ideológicas) para dar lugar à novas construções. Lopis (2017) salienta que o povo brasileiro, pela busca do progresso, tem admirado o novo e entendido que o moderno é melhor e mais adequado que o "velho". Nesse sentido, o autor antes mencionado ressalta:

Atualmente o conceito de patrimônio tem sido frequentemente discutido em nossa sociedade. Tanto por diferentes esferas sociais, quanto pelos órgãos de preservação. Isto acontece devido à urgência na salvaguarda de determinados elementos patrimoniais, como também pela recorrente destruição de monumentos/documentos devido às "necessidades" da modernidade. Como entender essa relação tão conflituosa entre o preservar e o transformar? Faz-se mister debater as relações entre o urbanismo que possui sua própria dinâmica, típica das sociedades modernas - e os elementos patrimoniais que são a representação simbólica de uma identidade, devem coexistir de maneira harmônica para a construção de uma sociedade que cresce e se transforma, mas que também preserva sua memória e sua história enquanto povo (LOPIS, 2017, p. 2).

Como os espaços patrimoniais caem no esquecimento, novos espaços são criados tornando-se novos outros espaços comuns. Ao passo que, revitalizar espaços, já existentes, trazem a memória coletiva urbana para a modernidade relacionando-a com as necessidades humanas atuais e harmonizando ambiências novas e antigas. Construções elencadas como patrimônio arquitetônico trazem além da colaboração para o desenvolvimento urbano um leque de possibilidades, pois auxiliam e protagonizam diversos setores da cidade (educação, cultura, turismo, renda, etc) podendo continuarem com suas funções antigas e/ou ainda ganharem novas. Nessa relação Gislon $(2015, \mathrm{~s} / \mathrm{p})$ ressalta que:

O patrimônio histórico, principalmente as edificações e os monumentos, são bastante procurados pelos turistas. Mas, essa categoria do turismo deve ser muito mais que visitas a museu, a bibliotecas e a monumentos históricos. Ela deve proporcionar também um importante contato entre o turista e as pessoas do local, do seu cotidiano e da sua cultura, 
e tem função importante para conservação da memória e identidade local, colaborando para que a cidade reconstitua a sua história. Em alguns locais históricos, são criados espaços privilegiados para os turistas, favorecendo sua presença.

Preservar não significa manter um local intocável, mas sim salvá-lo, garantindo a continuação histórica, tornando-o um local em que as pessoas possam beneficiarem-se de forma lucrativa e/ou cultural gerando conhecimento para os mais novos, e também, para os mais idosos. Preservar é manter viva a arquitetura para que possa ser observada, estudada e visitada - é não deixar que traços do passado percam-se com o tempo ou venham à ruinas, é observar o ato da preservação por um viés amplo e útil aliado ao desenvolvimento locar e regional pelas esferas da economia, da cultura e da cidadania.

\section{Considerações finais}

Devido a diversos fatores inerentes da contemporaneidade, o desenvolvimento urbano e regional, dá-se de forma muito veloz e, por vezes, completamente equivocado, pois percebese que não há um planejamento pré-existente nas cidades e as mesmas simplesmente vão crescendo e se desenvolvendo conforme a necessidade humana. No caso brasileiro nota-se uma grande modificação em seu crescimento, pois passou de um pais com maior potencial agrário para um pais urbanizado.

Percebe-se que a proteção do patrimônio arquitetônico das cidades, tanto em questões de manutenção quanto de revitalização, mostra-se como de grande importância, haja visto, que o desenvolvimento local depende de diversos fatores e dentre eles, com certeza, o da manutenção da memória urbana - vista como algo vivo e testemunho material de uma sociedade. São as ações humanas que definem o que fica em "pé" e o que é "tombado" - a consciência da população decide o que é importante, mantido, substituído ou demolido. É preciso entender a preservação do patrimônio arquitetônico como necessidade de referência histórica e cultural.

A preservação da arquitetura considerada como patrimônio histórico e cultural é de suma importância uma vez que colabora nos diversos setores, além de ser grande aliada para entender o desenvolvimento urbano e planejar o mesmo para o futuro. A estruturação do futuro é necessária, o entendimento adequado do presente e as interpretações do que já foi vivido, construído, sentido fundamentais, pois a manutenção e preservação são ações que devem caminhar juntas para que espaços urbanos sejam revitalizados e que voltem ao uso, além de criar novas ambiências ao redor das edificações patrimonializadas. 


\section{Referências}

AMARAL Claudio Silveira; MESSIAS, Pamela. A conservação do patrimônio arquitetônico: uma solução mais sustentável. Revista Nacional de Gerenciamento de Cidade, v. 04, n.28, p. 66-75, 2016.

BOGEA, Hiroshi. Importância da preservação da memória. In: Importância. [S. l.], 15 jun. 2011. Disponível em: http://www.hiroshibogea.com.br/importancia-da-preservacao-damemoria/. Acesso em: 23 jun. 2020.

CARDOSO, Viviane; GOLDENSTEIN, Marcelo; MENDES, Eduardo. A preservação do patrimônio cultural como âncora do desenvolvimento econômico. In: A preservação. [S. l.], 2009. Disponível em: https://web.bndes.gov.br/bib/jspui/bitstream/1408/1603/1/A\%20 BS $\% 2034 \% 20 \mathrm{~A} \% 20$ preserva $\% \mathrm{C} 3 \% \mathrm{~A} 7 \% \mathrm{C} 3 \% \mathrm{~A} 3 \mathrm{o} \% 20 \mathrm{do} \% 20$ patrim $\% \mathrm{C} 3 \% \mathrm{~B} 4$ nio $\% 20$ cultural $\% 20$ como $\% 20 \%$ C3\%A2ncora $\% 20$ do $\% 20$ desenvolvimento $\% 20$ econ\%C3\%B4mico_P.pdf. Acesso em: 20 maio 2020.

CHOAY, Françoise. A Alegoria do Patrimônio. Tradução Luciano Vieira Machado. 3. ed. São Paulo: Estação Liberdade: UNESP, 2006.

DELGADO, Luciano. A importância da proteção ao patrimônio cultural. In: A importância. [S. l.], 2018. Disponível em: https://www2.jornalcruzeiro.com.br/materia/856905/aimportancia-da-protecao-ao-patrimonio-cultural-imaterial. Acesso em: 20 maio 2020.

GISLON, Jacinta Milanez. Turismo e o Patrimônio Cultural: uma relação construída para interpretar, valorizar e preservar. In: Turismo. [S. l.], 10 out. 2015. Disponível em: https:// arquiteturahistoriaepatrimonio.wordpress.com/2015/10/10/turismo-e-o-patrimonio-culturaluma-relacao-construida-para-interpretar-valorizar-e-preservar/. Acesso em: 23 jun. 2020.

HARDT, Letícia Peret Antunes; Hardt, Carlos; Hardt, Marlos. Memória e cidade: contribuições à gestão do patrimônio cultural. Revista Confluencias Culturais. v. 6, n. 2.

INSTITUTO DO PATRIMÔNIO HISTÓRICO E ARTÍSTICO NACIONAL - IPHAN. Patrimônio cultural. Disponível em: http://portal.iphan.gov.br. Acesso em: 20 maio 2020.

IPHAN. Carta de Atenas. Assembleia do Congresso Internacional de Arquitetura Moderna. 1933.

LOPES, Erivania. Patrimônio histórico cultural: preservar ou transformar? Uma questão conflituosa. Patrimônio histórico cultural: preservar ou transformar? Uma questão conflituosa, [s. l.], 2017.

MIRANDA, Paulo. O estatuto da cidade e a proteção do patrimônio cultural. In: O estatuto. [S. l.], 2019. Disponível em: https://www.conjur.com.br/2019-dez-14/ambiente-juridicoestatuto-cidade-protecao-patrimonio-cultural. Acesso em: 21 maio 2020. 
OLIVEIRA, Tarcisio Dorn de; CALLAI, Helena Copetti. Cidade e arquitetura: (re) conhecer e preservar através da educação patrimonial. Plures Humanidades, Ribeirão Preto, v. 19, ed. 1, p. 135-146, 2018.

OLIVEIRA, T. D. de; LOPES, C. E. J. Monumento, monumentalidade, valor e poder: interações com a memória e preservação arquitetônica. METAgraphias: letra JK de JK de utopias políticas possíveis v.3, n.3, p. 1-17, 2018.

OLIVEIRA, Tarcisio Dorn de; MÜLLER, Jandha Telles Reis Vieira; WILDNER, Gabriel da Silva; LOPES, Caryl Eduardo Jovanovich. Educação e Arquitetura: a educação patrimonial preservando o patrimônio arquitetônico.Terr@Plural, Ponta Grossa, ano 2019, v. 13, n. 2, p. 577-588, 2019.

PIEPER, Daniela; BEHLING, Greici; DOMINGUES, Gabriella. Pertencimento, patrimônio e meio ambiente: um diálogo necessário para a sustentabilidade. In: Pertencimento.

Disponível em: https://www.eumed.net/rev/delos/21/pertencimento.html. Acesso em: 22 maio 2020.

RELAÇÕES e contradições: direito à cidade e patrimônio urbano. In: RIBEIRO, Claudio; SIMÃO, Maria. Relações e contradições: direito à cidade e patrimônio urbano. [S. 1.], 2014. Disponível em: https://www.anparq.org.br/dvd-enanparq-3/htm/Artigos/ST/ST-EPC-007-5RIBEIRO.SIMAO.pdf. Acesso em: 20 maio 2020.

SANTIN Janaína Rigo; SANTOS Mariana Mattei. Plano diretor e patrimônio histórico: análise a partir da constituição federal de 1988 e do estatuto da cidade. Revista de direito da cidade. vol. $08, \mathrm{n}^{\mathrm{o}} 2$. ISSN 2317-7721.

VIANNA, Tatiana; PACHECO, Pablo. A proteção do patrimônio histórico nos Planos Diretores dos municípios mineiros. In: A proteção. [S. l.], 2011. Disponível em: https:// ambitojuridico.com.br/cadernos/direito-ambiental/a-protecao-do-patrimonio-historico-nosplanos-diretores-dos-municipios-mineiros/. Acesso em: 22 maio 2020.

VILANOVA JUNIOR, Arere. A preservação do Patrimônio. In: A preservação. [S. l.], 2013. Disponível em: http://parquedaciencia.blogspot.com/2013/09/a-preservacao-do-patrimonio. html. Acesso em: 21 maio 2020. 